\title{
The Various Concepts of Curriculum and the Factors Involved in Curricula-making
}

\author{
Shao-Wen $\mathrm{Su}$ \\ Department of Applied English, National Chin-Yi University of Technology, Taiwan \\ Email: shaowen@ncut.edu.tw
}

\begin{abstract}
This paper aims at probing into the nature of curriculum by critically reviewing literature relevant to the term "curriculum." The multiple definitions associated with the term are inductively presented in conceptualizations so as to clarify what are the curricular issues that teachers should be concerned about in the school context. This paper then argues for the need to consider a broader spectrum of "curriculum" that embraces the whole aspects in the curriculum development process, for example, objectives, content, methodology, and evaluation of students, especially when a curricular review or evaluation is undertaken.
\end{abstract}

Index Terms - curriculum, curriculum development, curriculum evaluation, hidden curriculum, teaching methods, teaching objectives

\section{INTRODUCTION}

Curriculum is often one of the main concerns in the educational field. What kind of curricula should we offer to learners? Educators and teachers are concerned about what choices are to make about teaching content and methods. As for the parents, they would like to know what their children are going to learn. Learners are also concerned about what kinds of content they are going to have in class. "Curriculum" seems to be considered greatly as what teachers are going to teach and, in other words, what learners are going to learn. In fact, "curriculum" is also closely related to how well the learners learn - the outcomes. Thus, as an umbrella term, "curriculum" includes a lot of issues, for example, teaching curriculum, learning curriculum, testing curriculum, administrative curriculum and the hidden curriculum. This paper presents relevant literature associated with the term "curriculum" to help clarify what is the entity that we need to be concerned about in the school context.

\section{CURricular CONCEPTUALizations}

What is implied in the term "curriculum"? The answer to the question is hardly conclusive. There are a variety of definitions in relation to the term "curriculum." The indecisive nature of the term is owing to divided perceptions of stakeholders, e.g. students, educators, researchers, administrators, evaluators with their own agenda of emphasis in educational discourse. The void of uniformity reflects the complex nature of the concept of "curriculum" in its own right. Arguably, it is therefore necessary to clarify the conceptualization of the term curriculum, before the outset of any curriculum-related endeavours such as curriculum planning, implementation, evaluation, and empirical studies undertaken by administrators, teachers, researchers, and evaluators. In this vein, this paper seeks to clarify different conceptualizations of this term.

According to Pratt (1994, p.5) and Barrow and Milburn (1990, p.84), the word "curriculum" is derived from the Latin verb currere, "to run." "Currere" became a diminutive noun and meant a "racing chariot" or "race track." An extension was made by Cicero who associated the term with curriculum vitae that means "the course of one's life." He also associated it with curricula mentis that metaphorically refers to "the (educational) course of the mind." It was not until the nineteenth century that the term was commonly used in the educational field.

A great number of researchers or educators (e.g. Barrow \& Milburn, 1990; Beauchamp, 1977; Goodson, 1994; Longstreet \& Shane, 1993; Marsh, 1997; Wood \& Davis, 1978) have shed light on what curriculum is through their reviews of, or critical comments on, this term. An example is what Goodson (1994) describes of curriculum "as a multifaceted concept, constructed, negotiated and renegotiated at a variety of levels and in a variety of arenas" (p. 111). This view reflects the complex and interactive nature of curriculum. Longstreet and Shane (1993) reveal another side of curriculum which requires decision making:

Curriculum is a historical accident - it has not been deliberately developed to accomplish a clear set of purposes. Rather, it has evolved as a response to the increasing complexity of educational decision making (p.7).

Barrow and Milburn (1990) and Beauchamp (1977) note how the term "curriculum" is in some cases used in very limited contexts, but in other cases very broadly. With a little bit expansion, the author of this paper takes Beauchamp's view of conceptualization to examine the term "curriculum" in the order from the narrow to the broad. Definitions made by different researchers are provided to better understand the conception of curriculum.

A. Curricula as a Set of Objectives 
Curriculum can be seen as a means of achieving specific educational goals and objectives. In this sense, a curriculum can be regarded as a checklist of desired outcomes. In the curriculum development process, generally speaking, the objectives are clear and specific in behavioral and observable terms. The emphasis on objectives is the characterization of an objectives curriculum model. In this sense, the focus is on products or ends, and is also teacher-orientated or administrative-oriented. If it is the latter, curriculum is set by politicians without consulting teachers and very few of the teachers feel any sense of "ownership" for the material they are compelled to teach.

\section{B. Curricula as Courses of Study or Content}

Curriculum can be understood as a process of selecting courses of study or content (Beauchamp, 1977; Wood \& Davis, 1978). In this sense, a curriculum also either describes or prescribes the content and goals of formal instruction but lays the means of instruction out of the foreground of focus. Although this use of the curriculum appears similar to the above-mentioned definition-Curricula as a Set of Objectives-in terms of the inclusion of goals, in fact, there is a different focus. The first definition emphasizes the specification and prescription of instructional objectives whereas the definition here focuses on course content rather than learning objectives. The "courses" feature a variation of scope and amount. The definition here can be exemplified by the terminology of Wood and Davis (1978) in their monograph aiming at designing and evaluating higher education curricula in the University of California, Berkeley. They suggest that a curriculum be considered as a "totality of courses that constitute a course of study offered by an institution or followed by a student" (Wood \& Davis, 1978, p.16).

\section{Curricula as Plans}

A curriculum can be seen as a plan, or a sort of blueprint for systematically implementing educational activities. This sense of the term combines content with instructional methods and hence has a wider scope than the former two curricular paradigms because of the inclusion of methods. In this vein, Tom (1984) canvasses curriculum as "a plan for teaching or instruction" (p.89). Similarly, Pratt (1994) conceives it as "a plan for a sustained process of teaching and learning" (p.5) with a specific focus on content and the process of teaching and learning. What is worth noting is that this view of curriculum is not pragmatically equated with methods themselves in action. Pratt (1994) further explains this by stating that "actual teaching and learning is not curriculum, for curriculum refers to plans for instructional acts, not the acts of instruction themselves" (p.5). According to this view, curricula can be likened to construction blueprints. As a blueprint is not a building per se, a curriculum is not actual teaching or learning.

\section{Curricula as Documents}

Other people, for example, Brady (1995), view curriculum as a document--an outline of a course program that is written on a piece of paper. Thus, curriculum "has become associated with the official written programs of study published by ministries or departments of education, local authorities or boards of education, and commercial firms or teams of educational specialists working on specially funded projects" (Barrow \& Milburn, 1990, p.84). This view of the visual written document attached to curriculum derives from the need that, particularly in the phases of curriculum development and implementation, a written form has to be made to include a statement of objectives, content, method, and assessment. The presentation of the document purports to provide teachers with a model to follow in the curriculum process. In this sense, curriculum is synonymous with the term, "syllabus" (Barrow \& Milburn, 1990, p.84).

\section{E. Curricula as Experiences}

Instead of regarding curricula narrowly as formalized classroom content or prescriptive learning objectives, it may be useful to think of them more holistically as programs for experiences. Following this line of definition, one may recall what Marsh (1997) posits of curriculum as "an interrelated set of plans and experiences which a student completes under the guidance of the school" (p.5). That means: the relationship between "plans and experiences" is intertwined, where "plans" are attributed to planned curricula in advance and "experiences" refer to unplanned happenings in classrooms. Although planning is a precursor to action, it is important to acknowledge that unplanned happenings often occur in classroom settings. For this reason, Marsh (1997) states, "the actual curricula which are implemented in classrooms consist of an amalgam of plans and experiences..." (p.5). In other words, teaching is seldom entirely spontaneous or planned, but rather an interplay between impulse and intention; learning experiences extend beyond the classroom to activities outside the classroom (Marsh, 1997). In this sense, the experiences mean the possible learning experiential encounters that learners would engage themselves in inside or outside the classroom. All interactions that students are exposed to, in an academic environment, can be considered part of their curriculum. Hence, the whole range of experiences students are likely to undergo in the course of their education, such as school clubs, assemblies, excursions, fetes, and academic competitions, are parts of the extended curriculum. In this light, the experiences of teaching and learning can be viewed as post-curricular activities. In the same vein, the American Educational Research Association's Encyclopedia of Educational Research defines curriculum as "all the experiences that a learner has under the guidance of the school" (Kearney \& Cook, 1961, p.358). Barrow and Milburn (1990) echo this by describing a curriculum as "all the experiences that a child has in school" (p.85). Thus, the subject matter provided for students, the actions of teachers (attitudes and motivations) in the classroom, the actions of students (reactions, attitudes, and motivation), and the instructional materials can all be understood as facets of the experiential curriculum. 
This line of interpretation of curriculum gives rise to its link to "hidden curriculum," a term used to describe the unwritten social rules and expectations of behavior that are often not taught directly but are assumed to be known (Hyles, Truatman, \& Schelvan, 2004). "Hidden curriculum" hinges on location, situation, people, age, and culture; more importantly, it varies with the motive or purpose of the curriculum "architect" - the persons who lay the hidden curriculum in a given setting, such as teachers, administrators, or the school authority (Autismnetwork, n.d.). To further complicate the matter, "hidden curriculum" embraces a strong bond with culture, especially in the context of teaching and learning a language, as language and culture are two sides of a coin. Many cultures have unstated rules involving eye contacts, proximity, gestures, and ways of addressing people. Some cultures are high-context cultures where non-verbal cues are more important than the words that are said, whereas in low-context cultures, words, rather than non-verbal cues, express the real meaning of the conversation (Hyles, Truatman, \& Schelvan, 2004). The rules involving the non-verbal are all subsumed in the culture-related experience. In this light, curricula can even be conceptualized as broadly as culture. Joseph, Bravmann, Windschitl, Mikel, and Green (2000) expound this notion of curriculum-culture link.

Using a cultural lens, we can begin to regard curriculum not just as an object (content), but as a series of interwoven dynamics. Curriculum conceptualized as culture educates us to pay attention to belief systems, values, behaviors, language, artistic expression, the environment in which education takes place, power relationships, and most importantly, the norms that affect our sense about what is right or appropriate (p.19).

While "curriculum" is an interactive process developed among learners, teachers, materials, and the environment (Chen, 2007), it functions as a mirror that reflects cultural beliefs, social and political values and the organization. "Hidden curriculum" contains underestimated importance of the dynamics of human interactions in organizational behavior which are imperceptible, but have a powerful influence on institutional culture/climate (Nieto, 2007). In this sense, culture refers to the values and symbols that affect organizational climate. According to Owens (1987), the symbolic aspects of school activities (e.g., traditions, rites, and rituals) are subsumed, for these are "the values that are transmitted literally from one generation of the organization to another" (p. 168). The reason why hidden curriculum or learning culture counts lies in its important role in cultivating wholesome, successful students. The substance of hidden curriculum is learning acquired "by default" through participation in the activities of an institution, rather than by what has been directly taught (Atherton, 2009). The covert or unintended message sent to the students might be either an enhancement or a detriment of their learning; therefore, "hidden curriculum" gives cause for concern in students' learning experiences/processes. As "hidden curriculum" includes factors of social acceptability, vulnerability, safety, anxiety and self-image, it is crucial for the students to understand the world as the understanding empowers them to manage the world around them (Autismnetwork, n.d.). In fact, "all students must internalize a specific program of social norms for training in order to function effectively as members of a smaller society, the school, and later on as productive citizens of the larger American society" (Wren, 1993, p. 3). Therefore, the interactions between teachers and students as well as between administrators and students assist the students in shaping their attitudes and ideals (Henry, 1955).

One might argue against the likelihood to exhaust enumerating of the definitions of the term, "curriculum"; nevertheless, based on the definitions stated above in order, by and large, the curriculum elements refer to goals or objectives in the first definition and to content and goals in the second definition. They refer to teaching methods in addition to content and goals in the third definition and a combination of content, goals, methods and assessment in the fourth definition. In the fifth definition, the broadest one of all in scope and breadth, the curriculum elements encompass not only all four ingredients included in the third definition but also extracurricular activities, learning environment and even hidden curriculum as well as cultures that would entail learning experiences.

The enumeration of the definitions, thus, can be illustrated in algebra equations as follows.

1. Curricula as a set of objectives = goals or objectives

2. Curricula as courses of study or content $=$ content + goals

3. Curricula as plans $=$ content + goals + teaching methods

4. Curricula as documents $=$ content + goals + methods + assessment

5. Curricula as experiences $=$ content + goals + methods + assessment + extracurricular activities and learning environment + hidden curriculum + cultures

The linear alignment of the definitions helps grasp the meanings of the term in varied breadth, as shown in Figure 1.

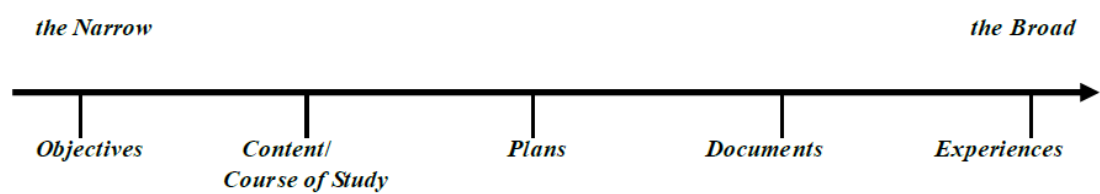

Figure 1. Linear Conceptualization of "Curriculum" from the Narrow to the Broad

Similarly, the concentric illustration demonstrates the inter-relationship among the definitions in distinct scope as follows. 


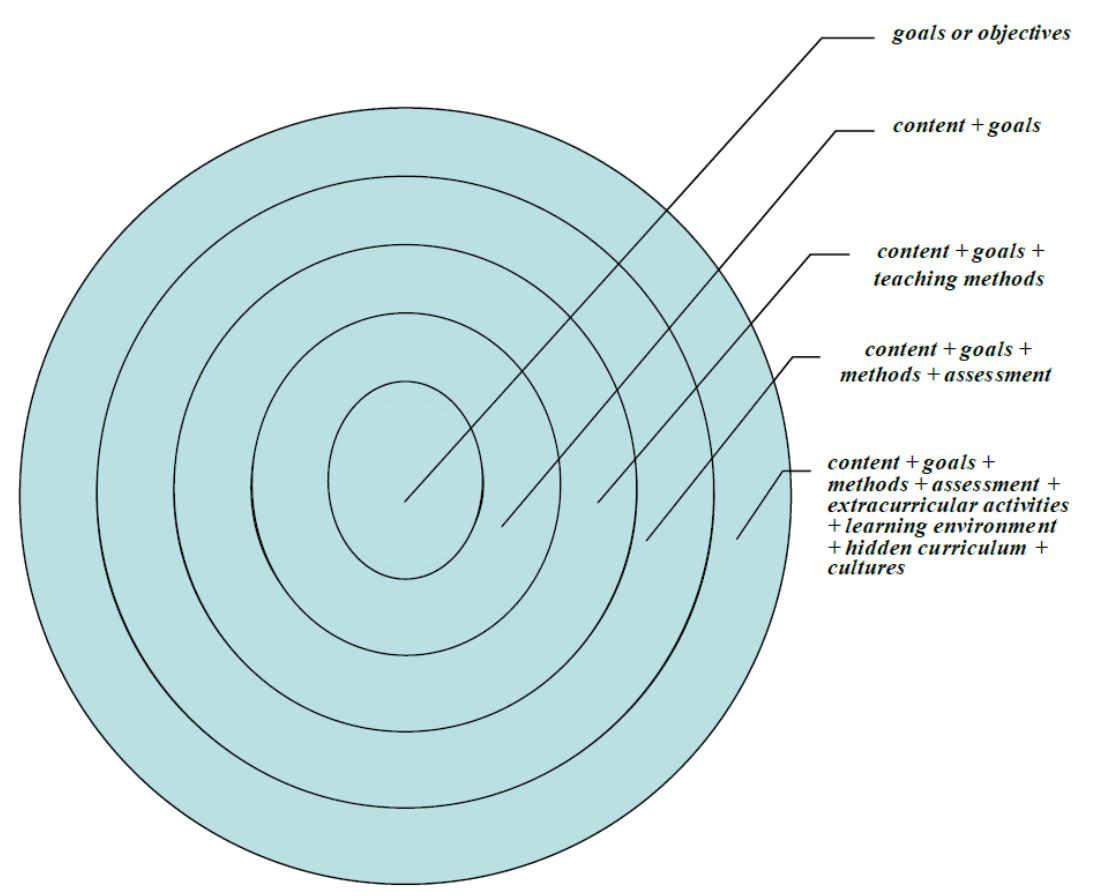

Figure 2. Concentric Ring of Conceptualization of "Curriculum”

\section{TOWARDS A BROADER VIEW OF CURRICULA}

Despite variations in perceiving the term "curriculum," according to Brady (1995, p.75) and Nunan (1988, p.4), the curriculum development process generally entails four elements: objectives, content, methods, and evaluation. Reynolds and Halpin (1982, p.23) have extended this view by considering "outcomes" as a fifth element of any curriculum by some educators. In this article, an even wider view of curriculum is recommended: one that includes the learning environment and considers the social dimensions of the schooling experience as an important element in achieving curricular effectiveness. Examples of application of the wider view of curriculum to curricular evaluation as such can go to Partlett and Hamilton (1976) in their illuminating evaluation, Walberg (1971) and Stufflebeam, Foley, Gephart, Guba, Hammond, Merriman, and Provus (1971) in their CIPP model, who include the situation or environment analysis while attributing the analysis to part of decision making and judgment. The situation analysis investigates all kinds of human and physical resources. These resources echo what Pratt (1980) is concerned about of educational "logistics" that refer to "the detailed planning of all the means--human, material, and administrative--for the delivery of instruction" (p.369). According to Pratt (1980), the logistics therefore include "materials, equipment, facilities, personnel, time, and cost" (p.369).

This recommended broader notion of curriculum embraces the previously mentioned essential elements of the curriculum process. This view seems oriented to Nunan's (1988) and Richards' (1984) views of an amalgamated process and product model in which a product-oriented ends-means model is fused with a process-oriented approach. A body of scholars (e.g. Brown, 1995; Richards, 1984; Richards, 2001) posits that curricular models include needs analysis, methodology, and evaluation as well as procedures for developing goals and objectives. Similarly, Nunan's learner-centred model (1988) suggests "needs analysis, goal identification, objective setting, materials development, learning activities, learning mode and environment and evaluation" (p.19) be included in as essential elements. In comparison, Nunan, however, advocates a broader scope of "curriculum" than Richards does; i.e. curriculum designers should consider learner issues such as learning difficulties and strategies as well as situational conditions such as resources available.

The rationale for adopting an integrated ends-means and process-oriented model are three-fold. First, as Nunan (1988, p.20) points out, curricula which do not consider both process and product features are too narrow in scope--they fail to highlight key features of the curriculum development, implementation, and revision process. A second important reason is that an integrated model avoids the general tendency for some product-oriented approaches to downplay the importance of methodology. According to Nunan (1988), it allows for "greater flow and integration between planning processes, implementation processes and evaluation" (p.20). The various curriculum development activities are viewed as ongoing processes within the teaching-learning process and in the evaluation circle. One may argue that looking at curriculum only from a single perspective such as content, outcomes or objectives would be unbalanced and limited in the scope. As a result, there is a possibility of bias, resulting in making false judgments and failing in understanding the complexity of curricula and aspects of teaching and learning. Especially, when one step further is taken to do the evaluation of curricula before initiating curriculum reforms, one needs to take into consideration all aspects of curricula. 


\section{CONCLUSION}

How a curriculum is planned poses itself as one of the most important factors that predetermines the success and effect of curricular implementation. Curriculum planning and instruction are closely connected to each other, and so are the curriculum planning and outcomes. In order to achieve satisfactory outcomes, the issue as to what the essence of "curriculum" is about should be clarified before any curricular endeavors, such as curriculum planning, implementation, and even evaluations, are attempted. This paper has sought to illustrate the nature of the term "curriculum" by looking into the literature associated with it. One might find the relevant literature on the term is exhaustive, and the endeavor to illustrate all the entries would be a mission impossible. In fact, probing into the related literature does not act as the main thrust of the paper but paves the way to argue for a broader view of curriculum and the curriculum development process, especially when a curricular review or evaluation is undertaken.

\section{ACKNOWLEDGEMENT}

The author of this paper would like to extend gratitude to National Science Council in Taiwan for its research grants (NSC99-2410-H-167-002). Special appreciation also goes to Dr. Tim Newfields, an associate professor in Toyo University, Tokyo, Japan for his insightful feedback on this paper.

\section{REFERENCES}

[1] Atherton, J. S. (2010). Managing the hidden curriculum. Retrieved July 11, 2011, from http://www.doceo.co.uk/tools/hidden.htm

[2] Autismnetwork (n.d.). Hidden curriculum. Retrieved January 9, 2011, from http://www.autismnetwork.org/modules/social/hidden/index.html

[3] Barrow, R., \& Milburn, G. (1990). A critical dictionary of educational concepts. New York: Harvester Wheatsheaf.

[4] Beauchamp, G. (1977). Basic components of a curriculum theory. In A. Bellack \& H. Kliebard (eds.), Curriculum and evaluation (p.22). Berkeley: McCutchan.

[5] Brady, L. (1995). Curriculum development. Sydney: Prentice Hall.

[6] Brown, J. D. (1995). The elements of language curriculum: A systematic approach to program development. Boston, MA: Heinle \& Heinle Publishers.

[7] Chen, Y.-U. H. (2007). The role of culture in an EFL curriculum of the $21^{\text {st }}$ century. Selected Papers from the Sixteenth International Symposium on English Teaching (pp. 119-129). Taipei, Taiwan: Crane.

[8] Goodson, I. F. (1994). Studying curriculum. New York: Teachers College Press.

[9] Henry, J. (1955). Docility or giving the teacher what she wants. Journal of Social Issues, 11, 41-53.

[10] Hyles, B. S., Truatman, M. L., \& Schelvan, R. L. (2004). The hidden curriculum: Practical solutions for understanding unstated rules in social situations. USA: Autism Asperger Publishing Co.

[11] Joseph, P. B., Bravmann, S. L., Windschitl, M. A., Mikel, E. R., \& Green, N. S. (2000). Cultures of curriculum. Mahwah, NJ: Lawrence Erlbaum Associates.

[12] Kearney, N. C., \& Cook, W. W. (1961). Curriculum. In C. W. Harris (Ed.), Encyclopedia of educational research (pp. 358-365). New York: Macmillan and American Educational Research Association.

[13] Longstreet, W. S., \& Shane, H. G. (1993). Curriculum for a new millennium. Boston: Allyn and Bacon.

[14] Marsh, C. J. (ed.) (1997). Perspectives: Key concepts for understanding curriculum 1. London \& Washington, D.C.: The Falmer Press.

[15] Nieto, S. (2007). Affirming diversity: The sociopolitical context of multicultural education (5 $5^{\text {th }}$ ed.). Boston: Pearson education.

[16] Nunan, D. (1988). The learner-centered curriculum. Cambridge: Cambridge University Press.

[17] Owens, R. (1987). Organizational behavior in education ( $3^{\text {rd }}$ ed.). New Jersey: Prentice-Hall.

[18] Partlett, M., \& Hamilton, D. (1976). Evaluation as illumination: A new approach to the study of innovatory programs. In D. A. Tawney (Ed.), Curriculum evaluation today: Trends and implications (pp. 125-136). London: Macmillan Education.

[19] Pratt, D. (1980). Curriculum design and development. New York: Harcourt Brace Jovanovich, Inc.

[20] Pratt, D. (1994). Curriculum planning: A handbook for professionals. Fort Worth: Harcourt Brace College Publishers.

[21] Reynolds, J. B., \& Halpin, D. (1982). Curriculum development. In P. J. Hills (ed.), A dictionary of education (pp.22-26). London: Routledge and Kegan Paul.

[22] Richards, J. C. (1984). Language curriculum development. RELC Journal, 15(1), 1-29.

[23] Richards, J. C. (2001). Curriculum development in language teaching. Cambridge: Cambridge University Press.

[24] Stufflebeam, D. L., Foley, W. J., Gephart, W. J., Guba, E. G., Hammond, R. L., Merriman, H. O., \& Provus, M. M. (1971). Educational evaluation and decision making. Itasca, IL: F. E. Peacock Publishers, Inc.

[25] Tom, A. R. (1984). Teaching as a moral craft. New York: Longman.

[26] Walberg, H. J. (1971). Models for optimising and individualizing school learning. Interchange, 2, 15-27.

[27] Wren, D. (1993). A comparison of the theories of adolescent moral development of Lawrence Kohlberg and Carol Gilligan: Alternative views of the hidden curriculum. Unpublished doctoral dissertation, Lehigh University.

[28] Wood, L., \& Davis, B. G. (1978). Designing and evaluating higher education curricula. AAHE-ERIC/Higher Education Research Report No. 8. Washington, D. C.: The American Association for Higher Education. 


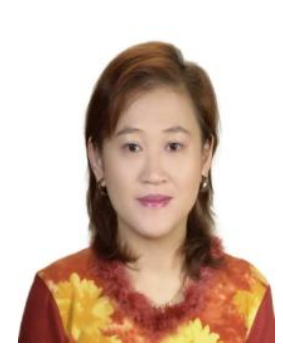

Shao-Wen Su was born in Tainan, Taiwan. She received her Doctor of Philosophy degree in Education from the University of Newcastle, Australia in 2003, an MA in English Literature and Language, Taiwan in 1990 and a BA in Foreign Literature and Languages, Taiwan in 1987.

She teaches as an associate professor at the Department of Applied English, National Chin-Yi University of Technology, Taiwan. She has been teaching EFL in colleges and universities for nearly 19 years.

Her research interests mainly include areas of English writing, English literature and ESP instructions as well as curriculum design and evaluation.

Her recent publications include: (1) Su, Shao-Wen \& Chung-Hsiang Liu (2012/May). Teaching listening comprehension skills: A test-orientated approach. Journal of Language Teaching and Research, 3 (forthcoming). (2) Chen, Yuan-Shan \& Su, Shao-Wen (2012/April). A genre-based approach to teaching EFL summary writing. ELT Journal, 66(2) (forthcoming). (3)_Su, Shao-Wen (2011/August). A content-based English listening and speaking class for hospitality purposes. Theory and Practice in Language Studies, 8 (forthcoming). (4) Su, Shao-Wen (2010). English placement practice and instruction: A needs analysis from the perspective of technological university students. Journal of National Kaohsiung Normal University, 29. (5) Su, Shao-Wen (2010). Motivating and justifiable: Teaching Western literature to EFL students at a Taiwanese university of science and technology. TESL-EJ, 14(1). (6) Su, Shao-Wen (2009). A study of graduation threshold of English competency from the perspective of EFL teachers of technological institutions in Southern Taiwan. Journal of National Kaohsiung Normal University, 27. (7) Su, Shao-Wen (2009). Perceptions on elevating academic research capability: A study from the perspective of humanities and social science teachers in a private technological university. Chung Cheng Educational Studies, 8(2). (8) Su, Shao-Wen (2009). A reflection on the teaching of foreign language teachers. Journal of Cheng Shiu University, 22. (9)

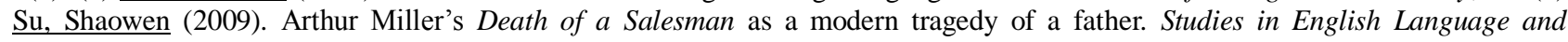
Literature, 23. (10) Su, Shao-Wen (2008). English teaching materials, methodology, and student assessment: A comparative study of

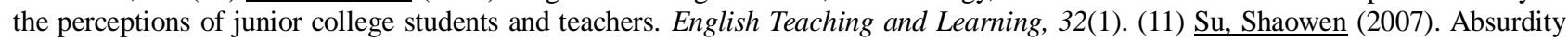
and certitude: Waiting for Godot as the Theatre of the Absurd. Studies in English Language and Literature, 20. (12) Su, Shao-Wen (2007). Tea or coffee: A study of the beverage choice pattern and its affecting factors at teatime in Kaohsiung, Taiwan. Asia Pacific Management Review, 12(4). (13) Su, Shaowen (2006). Beyond the unconscious: "Gaze" in Peter Shaffer's Equus. Tamkang Review, 36(3). (14) $\mathrm{Su}$, Shao-Wen (2005). Graduation threshold of English competency: A needs analysis from the perspective of technological institute students. Educational Review, 24.

Dr./Professor Su is a member of ETRA (The English Teaching and Research Association) and ETA (English Teachers' Association) in Taiwan. She is also one of the editors of Journal of Language Teaching and Research. 